\title{
JOHN WATT BUTTERS
}

Mr J. W. ButTers, M.A., B.Sc., who died on 11th January, 1946, at the age of 82 , had a long connection with the Edinburgh Mathematical Society and with educational circles in Scotland. He was a member of the Society from the beginning of its fifth Session, 1886, and rarely missed a meeting. He held office as a member of the Committee continuously from 1889 to 1902 , and from 1936 to 1938, was Secretary (1896-99), Vice-President (1899-1900) and President (1900-01). As a young man he took an active part in the meetings, both with his own contributions and with expositions of the work of others submitted for publication. One research paper and a good many notes of pedagogic value and originality were published in the Proceedings between 1897 and 1903, and he gave substantial assistance in the rather laborious preparation of the second Index Volume to the Proceedings and Mathematical Notes. He was also for fifty years a Fellow of the Royal Society of Edinburgh, and was on the Council of the Scottish Geographical Society.

His career as a teacher included short periods at Aberystwyth and at James Gillespie's School, Edinburgh, followed by eleven years at George Heriot's School, Edinburgh; but his main work was done at the Academy, Ardrossan, of which he was Rector from 1899 to 1928. $\mathrm{He}$ gave valuable service to education through his membership of the Council of the Educational Institute of Scotland and of the Business Committee of the General Council of Edinburgh University.

His friend, Dr J. B. Clark, writes: “Mr Butters was a man of exceptionally wide intellectual interests. His teaching was characterised by a most inspiring freshness and clarity. He was one of the most upright men I have known; I cannot imagine that he would ever lend himself to any mean or unworthy act, and he had a very passionate love of truth. Such qualities must have involved an influence on his pupils which was wholly for good. He was a keen nature-lover, and the fells of the Lake District, the peaks of Arran, and the bens of the Highlands had for him an irresistible attraction. He was, too, a most loyal friend, and all of us who were privileged to know him held him in the highest regard."

$\mathrm{He}$ is survived by his widow, a sister of Dr A. Crichton Mitchell, and by a son and two daughters.

I. M. H. Etherington. 